\title{
EL DERECHO DE SUFRAGIO EN TIEMPOS DE PANDEMIA
}

\author{
Óscar Sánchez Muñoz \\ Profesor Titular de Derecho Constitucional \\ Universidad de Valladolid
}

\begin{abstract}
Cómo citar este artículo / Citation: Sánchez Óscar. (2020). El Derecho de sufragio en tiempos de pandemia. Biglino Campos, P.; Durán Alba, F. Los Efectos Horizontales de la COVID sobre el sistema constitucional: estudios sobre la primera oleada,

Colección Obras Colectivas,

Fundación Manuel Giménez Abad, Zaragoza.

DOI: https://doi.org/10.47919/FMGA.OC20.0012
\end{abstract}

SUMARIO: I. INTRODUCCIÓN. II. LA SUSPENSIÓN DE PROCESOS ELECTORALES. 1. La inexistente habilitación legal para suspender procesos electorales ya convocados. 2. La razonabilidad y la proporcionalidad de las medidas de suspensión de los procesos electorales. III. DESARROLLO DEL PROCESO ELECTORAL Y MEDIDAS PROTECTORAS. 1. La flexibilización del voto por correspondencia: un cuestionable recorte de garantías. 2. La privación del derecho de sufragio de personas infectadas o sospechosas de estarlo. IV. BIBLIOGRAFÍA

\section{INTRODUCCIÓN}

Uno de los pilares del principio democrático es, sin duda, la exigencia de que la ciudadanía pueda confirmar la continuidad de los cargos electos o poner fin a su mandato dentro de un plazo definido constitucionalmente. Dicho esto, es evidente que, en determinadas situaciones, como pueden ser catástrofes naturales, medioambientales o sanitarias, la celebración de elecciones puede ser, de hecho, imposible o suponer un riesgo para la vida o la integridad física de las personas. 
La pandemia de covid-19 ha supuesto un reto para el funcionamiento normal de las instituciones democráticas en todo el mundo y, de manera particular, ha tenido un impacto considerable sobre el ejercicio de los derechos de participación política. Decenas de países se han visto obligados a posponer procesos electorales, mientras que otros muchos han celebrado elecciones con medidas especiales que, en ocasiones, han podido suponer restricciones a los derechos y libertades de los ciudadanos.

En nuestro país, las elecciones autonómicas en las comunidades del País Vasco y Galicia, inicialmente previstas para el 5 de abril, fueron suspendidas y finalmente pospuestas hasta el 12 de julio. El desarrollo de dichos procesos se vio afectado por distintas medidas de protección de la salud pública, incluyendo la denegación del ejercicio del derecho de voto a las personas infectadas por el virus, sometidas a confinamiento forzoso.

El desarrollo de procesos electorales durante una situación de pandemia plantea cuestiones jurídicas que se sitúan en planos diversos. A ellas dedicaremos las diferentes partes del presente trabajo: en primer término, abordaremos la cuestión relativa a la decisión sobre la suspensión de las elecciones. En segundo término, una vez que los procesos electorales están en marcha, analizaremos algunos de los posibles conflictos que pueden plantearse entre el derecho de participación política y las medidas adoptadas por los poderes públicos para la protección de los derechos a la salud, la vida y la seguridad de las personas.

\section{LA SUSPENSIÓN DE PROCESOS ELECTORALES}

Ante la expansión de la pandemia de covid-19, en numerosos países se ha decidido la suspensión de procesos electorales y su retraso hasta fechas en las que las condiciones fuesen más favorables ${ }^{1}$. De hecho, en el momento álgido

\footnotetext{
${ }^{1}$ Sólo en el ámbito del Consejo de Europa, la plataforma Elecdata da cuenta del retraso de procesos electorales en Austria (elecciones regionales, del 15 de marzo al 13 de septiembre, y del 29 de marzo al 13 de septiembre); Francia (segunda vuelta de las elecciones locales, del 22 de marzo al 28 de junio); Italia (referéndum, del 19 de marzo al 20-21 de septiembre, elecciones regionales del Valle de Aosta, del 19 de abril primero al 10 de mayo y posteriormente al 20-21 de septiembre, elecciones regionales en otras 6 regiones, del 31 de mayo al 20-21 de septiembre); Macedonia del Norte (elecciones parlamentarias, del 12 de abril al 15 de julio); Rusia (referéndum constitucional, del 22 de abril al 25 de julio-1 de julio);
} 
de la primera ola de la pandemia son escasos los ejemplos de elecciones mantenidas $^{2}$. La decisión de aplazar procesos electorales como consecuencia de crisis de salud pública ya se había adoptado en 2001 en el Reino Unido, cuando se retrasaron las elecciones generales y locales a causa de una epidemia de fiebre aftosa y, más recientemente en la República Democrática del Congo, cuando fueron retrasadas las elecciones presidenciales previstas para el 2018.

En la mayoría de los lugares, la suspensión o el aplazamiento de los procesos electorales se han visto como soluciones razonables ante la gravedad de la situación y no han generado una gran contestación, ni en la comunidad jurídica, ni en la opinión pública, pero en determinados casos -como el aplazamiento por un año de las elecciones al Consejo legislativo de Hong Kong, los sucesivos retrasos de las elecciones presidenciales en Bolivia o el simple planteamiento por parte de Donald Trump de la posibilidad de retrasar las elecciones presidenciales en los EEUU- sí que se ha suscitado la posible instrumentalización política de estas decisiones. La conflictividad generada en estos casos muestra a las claras que no se trata de decisiones inocuas y que, en situaciones de elevada tensión política, pueden llegar a afectar a la esencia de la propia democracia.

En términos jurídico-constitucionales, la exigencia de que la ciudadanía pueda confirmar la continuidad de los cargos electos o poner fin a su mandato dentro de un plazo definido constitucionalmente constituye uno de los pilares del principio democrático y, en coherencia con ello, dicha exigencia ha quedado también plasmada en términos subjetivos en el artículo 23.1 de la Constitución al reconocer el "derecho a participar en los asuntos públicos, directamente o por medio de representantes, libremente elegidos en elecciones periódicas por sufragio universal”.

Croacia (elecciones parlamentarias, del 26 de abril al 21 de julio); Reino Unido (elecciones locales, del 7 de mayo hasta el 6 de mayo de 2021); Polonia (elecciones presidenciales, primera vuelta del 10 de mayo al 28 de junio, segunda vuelta del 24 de mayo al 12 de julio). Fuente: https://www.coe.int/fr/web/electoral-assistance/elecdata-covid-impact.

${ }^{2}$ En Europa se pueden señalar sólo los casos de Francia, que mantuvo la primera vuelta de sus elecciones locales (15 de marzo), Alemania, que mantuvo las elecciones del Land de Baviera (15 y 29 de marzo), y Suiza, que mantuvo las elecciones cantonales de Turgovia (15 de marzo) y Schwytz (22 de marzo). Fuera de Europa, destaca sobre todo el caso de Corea de Sur, que mantuvo sus elecciones parlamentarias del 15 de abril. 
Al recoger así el principio de periodicidad, nuestra Constitución no hace sino seguir la línea marcada por la Declaración Universal de los Derechos Humanos, que en su artículo 21.3 señala que la voluntad del pueblo "se expresará mediante elecciones auténticas que habrán de celebrarse periódicamente", y por los principales instrumentos internacionales sobre derechos humanos ratificados por España que establecen el derecho de los ciudadanos a "votar y ser elegidos en elecciones periódicas" (artículo 25 del Pacto Internacional de Derechos Civiles y Políticos), y más específicamente la obligación de los Estados de celebrar las elecciones "a intervalos regulares" (artículo 3 del Protocolo Adicional no 1 al Convenio Europeo de Derechos Humanos) $)^{3}$.

Dicho lo anterior, a la hora de hacer realidad el derecho de participación de la ciudadanía no sólo importan los principios de periodicidad o de regularidad, también es preciso cumplir con otras exigencias básicas del Derecho electoral, como son los principios de sufragio universal, libre, igual y secreto o la garantía de la igualdad de oportunidades entre los competidores electorales. Esto implica, por tanto, que las elecciones deben llevarse a cabo en condiciones de libertad y de seguridad para todas las personas intervinientes en el mismo. Estos principios de libertad y seguridad, que se aplican en situaciones de conflicto, son igualmente aplicables a una situación de pandemia. Posponer elecciones puede parecer, a priori, una solución poco democrática, pero celebrarlas en condiciones que no aseguren una comunicación previa libre y que no garanticen la seguridad de las personas implicadas puede ser una solución aún menos respetuosa con las más elementales garantías democráticas y puede acabar dañando a la autenticidad del resultado y, por ende, a la legitimidad del proceso en su conjunto.

Los tratados internacionales sobre derechos humanos, dado su grado de generalidad, no contienen ninguna previsión concreta sobre suspensión o aplazamiento de procesos electorales. En cambio, si descendemos a documentos de tipo técnico o de soft law sí que encontramos referencias al carácter excepcional de estas decisiones. Por ejemplo, en el "Manual sobre los aspectos legales, técnicos y humanos de las elecciones", elaborado por el Centro de Naciones Unidad para los Derechos Humanos, se indica

\footnotetext{
${ }^{3}$ Son múltiples los tratados y documentos internacionales que hacen referencia, de una u otra forma, a este principio. Véase la referencia detallada en De Guttry (2020: XI y ss.).
} 
expresamente que "el aplazamiento de elecciones programadas por razones de emergencia pública puede permitirse en ciertas circunstancias limitadas, pero sólo si y en la medida estrictamente requerida por las exigencias de la situación" (United Nations Center for Human Rights, 1994; citado por De Guttry, 2020: XV).

La Comisión de Venecia, en su "Informe provisional sobre las medidas adoptadas en los Estados miembros de la UE como resultado de la crisis del Covid-19 y su impacto en la democracia, el Estado de derecho y los derechos fundamentales" (2020) advierte de que "la celebración de elecciones en situaciones de emergencia puede resultar problemática", al verse afectados diversos derechos de los electores (párrafo 102), pero, al mismo tiempo, también reconoce que "no celebrar elecciones puede ser problemático desde el punto de vista del derecho a elecciones periódicas" (párrafo 103). Por consiguiente, sea una u otra la decisión adoptada, ya sea mantener las elecciones con medidas especiales o bien aplazarlas, la clave para valorar la legitimidad de dicha decisión es el principio de proporcionalidad:

"[T]oda restricción destinada a garantizar la celebración puntual de elecciones debe ponderarse con la limitación del derecho a elecciones libres debido a la situación de emergencia y, a la inversa, el aplazamiento de las elecciones debe ponderarse con el riesgo de celebrarlas durante la situación de emergencia" (párrafo 106).

Por ello, aunque nuestro texto constitucional no diga nada expresamente sobre la posibilidad de suspensión o aplazamiento de los procesos electorales en situaciones de emergencia, al tratarse de medidas que suponen una clara limitación del derecho de participación del artículo 23 de la Constitución, habrán de adoptarse con una base legal, servir a una finalidad compatible con el orden constitucional y respetar el principio de proporcionalidad.

Si nos detenemos en algunos ejemplos comparados de lo que ha sucedido durante la pandemia, comprobaremos que en todos los casos las decisiones se han adoptado con una base legal más o menos clara.

En el Reino Unido, la decisión de suspender las elecciones locales fue tomada por el Gobierno siguiendo una recomendación de la Electoral Commission, 
pero antes de adoptar formalmente dicha decisión fue necesaria una habilitación legal, que se produjo con la llamada Coronavirus Act, aprobada por el Parlamento el 25 de marzo de $2020^{4}$, la cual le otorgó al Gobierno una serie de poderes excepcionales en la situación de emergencia, entre los cuales el de posponer procesos electorales (secciones 59 y ss.).

En Francia, tras la polémica suscitada por la celebración de la primera vuelta de las elecciones municipales el 15 de marzo, en plena fase ascendente de la pandemia, el Presidente de la República anunció el día 16 la suspensión de la segunda vuelta, prevista para el día 22 de marzo, suspensión en principio sine die, aunque más adelante se fijó la fecha del 28 de junio para la celebración de los comicios. La medida, que no está prevista en el Código Electoral francés, se adoptó formalmente a través del Decreto $n^{\circ}$ 2020-267, de 17 de marzo que derogaba parcialmente el Decreto no 2019-928, que convocaba las elecciones, siendo regularizado posteriormente mediante la Ley no 2020-290, de 23 de marzo de 2020. Previamente, el Consejo de Estado se había pronunciado sobre el Proyecto de ley y había avalado la medida en virtud de las circunstancias excepcionales. Posteriormente, el Consejo Constitucional ${ }^{5}$ también ha considerado la medida conforme con la Constitución, precisando que el legislador sólo puede autorizar una modificación del desarrollo de las operaciones electorales cuando la misma esté "justificada por un imperativo de interés general" y siempre que la regulación respete el derecho de sufragio y los principios de sinceridad del voto y de igualdad. En el caso concreto, la finalidad de evitar que la campaña y la votación contribuyesen a la propagación del virus en un contexto de confinamiento de la población fue considerada como un motivo plenamente válido. Asimismo, el Consejo tampoco consideró que la regulación adoptada en la ley impugnada atentaba contra el derecho de sufragio, pues no había sido probado que pudiese suponer un daño para la participación, ni para la sinceridad del escrutinio. Al contrario, según el Consejo, numerosas medidas adoptadas por el legislador iban precisamente dirigidas a asegurar la continuidad de las operaciones electorales, la igualdad entre los candidatos y la sinceridad del voto.

\footnotetext{
${ }^{4}$ Coronavirus Act 2020. An Act to make provision in connection with coronavirus; and for connected purposes. Disponible en: https://www.legislation.gov.uk/ukpga/2020/7/contents .

${ }^{5}$ Decisión del Consejo Constitucional de 17 de junio de 2020, $\mathrm{n}^{\circ}$ 2020-849 QPC. Disponible en: https://www.conseil-constitutionnel.fr/decision/2020/2020849QPC.htm .
} 
En Italia, el retraso del referéndum constitucional se llevó a cabo mediante la revocación del Decreto de convocatoria del mismo, dictada por el Presidente de la República a solicitud del Consejo de Ministros ${ }^{6}$. En cuanto a las elecciones regionales de Valle de Aosta, Véneto, Liguria, Toscana, las Marcas, Campania y Apulia, previstas para diversas fechas, fueron todas ellas retrasadas hasta el 20-21 de septiembre. No obstante, hay que distinguir entre la situación del Valle de Aosta, que es una región de estatuto especial, del resto.

En el caso de las 6 otras regiones, de estatuto ordinario, el retraso de la fecha se hizo antes de que las elecciones hubieran sido convocadas y fue autorizado por un Decreto-ley del 20 de abril de 2020, convertido posteriormente en ley ${ }^{7}$, que derogaba el artículo 5 de la ley de 2 de junio de 2004, ampliando el mandato de los órganos electivos de dichas regiones, con carácter excepcional, a la luz del estado de emergencia sanitaria.

En el caso de Valle de Aosta, que es una región de estatuto especial, las elecciones inicialmente previstas para el 19 de abril, ya habían sido convocadas por Decreto del Presidente de la Región de 5 de febrero de 2020. Posteriormente, a través de un nuevo Decreto de 10 de marzo, las elecciones fueron fijadas para el 10 de mayo. Más tarde, un nuevo Decreto de 23 de marzo retrasó los comicios una vez más, pero dejando la fecha pendiente de lo que determinase por Decreto el Presidente de la Región una vez que expirase el estado de emergencia sanitaria decretado por el Consejo de Ministros. Finalmente, las elecciones se convocaron por Decreto del Presidente de la Región de 20 de julio de 2020. Para fijar la fecha, el Presidente se atuvo al principio de concentración de elecciones establecido por el Decreto-Ley de 20 de abril de 2020, al que nos hemos referido anteriormente. Previamente, mediante una ley regional ${ }^{8}$ se había establecido la modalidad de celebración de las elecciones regionales en el supuesto de que se celebrasen coincidiendo con un referéndum constitucional.

\footnotetext{
${ }_{7}^{6}$ Decreto de 5 marzo 2020, que revoca el Decreto de 28 de enero de 2020.

${ }^{7}$ Decreto-ley $n^{\circ} 26$, del 20 de abril de 2020, de disposiciones urgentes en materia de consultas electorales para el año 2020, convertido, con modificaciones, en la Ley n 59 , de 19 de junio de 2020.

${ }^{8}$ L.R. 8/2020, que modifica el artículo 48 de la L.R. 5/2020.
} 
Este breve recorrido por el Derecho comparado tiene como finalidad comprobar que, en los casos citados, las decisiones de retraso de los procesos electorales han sido adoptadas en términos generales con una base legal suficiente.

¿Qué ha sucedido en nuestro país? Como hemos avanzado en la introducción, las elecciones autonómicas en las comunidades del País Vasco y Galicia, inicialmente previstas para el 5 de abril, fueron suspendidas y finalmente pospuestas hasta el 12 de julio. La primera cuestión que debemos plantearnos es si dicha suspensión y posterior retraso contó con la adecuada cobertura legal.

En el País Vasco y en Galicia, las elecciones autonómicas habían sido convocadas mediante sendos decretos de 10 de febrero de $2020^{9}$. Con posterioridad a dicha convocatoria, la evolución de la pandemia, en particular tras la adopción del estado de alarma mediante el Real decreto 463/2020, de 14 de marzo, así como el conjunto de medidas adoptadas tanto a nivel estatal, como a nivel autonómico, para hacer frente a la emergencia sanitaria, determinaron la aprobación, en ambas comunidades autónomas de nuevos decretos mediante los cuales los procesos electorales quedaban en suspens $0^{10}$. En concreto, la fórmula utilizada en ambos casos fue la de "dejar sin efecto la celebración de las elecciones", señalando que la convocatoria "se activará una vez levantada la declaración de emergencia sanitaria" -en el caso del País Vasco- o "una vez levantada la declaración del estado de alarma y la situación de emergencia sanitaria" -en el caso de Galicia- ${ }^{11}$.

Dos son las preguntas que, en mi opinión, debemos plantearnos a la hora de analizar las decisiones adoptadas en el País Vasco y en Galicia: la primera,

\footnotetext{
${ }^{9}$ Decreto 2/2020, de 10 de febrero, del Lehendakari, por el que se disuelve el Parlamento Vasco y se convocan elecciones; Decreto 12/2020, de 10 de febrero, del Presidente de la Xunta, de disolución del Parlamento de Galicia y de convocatoria de elecciones.

${ }^{10}$ Decreto $7 / 2020$, de 17 de marzo, del Lehendakari, por el que deja sin efecto la celebración de las elecciones al Parlamento Vasco del 5 de abril de 2020, debido a la crisis sanitaria derivada del Covid-19, y se determina la expedición de la nueva convocatoria; Decreto 45/2020, de 18 de marzo, por el que se deja sin efecto la celebración de las elecciones al Parlamento de Galicia de 5 de abril de 2020 como consecuencia de la crisis sanitaria derivada del Covid-19. Un análisis pormenorizado de estos decretos lo encontramos en Cebrián Zazurca (2020: 3 y ss.).

${ }^{11}$ Nótese el matiz de la ausencia de la referencia expresa al estado de alarma en el caso del País Vasco. Según Cebrián Zazurca (2020: 29), es el decreto gallego el que, de forma incorrecta, parece establecer que la declaración del estado de alarma condiciona la convocatoria de las elecciones, cuando ello no es así.
} 
sobre la legalidad de dichas medidas; la segunda, sobre la razonabilidad y la proporcionalidad de las mismas.

\section{La inexistente habilitación legal para suspender procesos electorales ya convocados}

Ante la cuestión de si la decisión de suspender un proceso electoral ya convocado cuenta con algún tipo de cobertura normativa en nuestra legislación, la respuesta no puede ser más que negativa. Como ha señalado, entre otros, Presno Linera (2020a), ni en el conjunto de artículos de la LOREG que tienen la consideración de básicos en virtud de la DA $2^{\underline{a}}$ de dicha ley, ni en las legislaciones electorales de las dos comunidades autónomas concernidas, se encuentra ninguna disposición que permita la suspensión de los procesos electorales una vez convocados. Tampoco la declaración del estado de alarma puede servir de base a tal decisión, pues no habilita para restringir el derecho de participación política ${ }^{12}$.

Ahora bien, resulta evidente que puede haber situaciones de fuerza mayor en las que el desarrollo de un proceso electoral sea imposible o no reúna las mínimas condiciones para ser considerado válido. La cuestión en estos casos es saber cuál sería la vía jurídicamente adecuada para poder suspender el proceso electoral con las máximas garantías para el derecho de participación política de los ciudadanos. ¿Quién puede tomar esa decisión? ¿A través de qué instrumento? ¿Con qué controles?

La legislación electoral vigente sólo hace referencia a las situaciones de fuerza mayor en los artículos 84.2 y 95.2 de la LOREG. El primero se refiere a la suspensión de la votación en mesas determinadas y el segundo a la suspensión del acto del escrutinio, también en mesas determinadas. Ninguno de estos dos preceptos resulta aplicable a las elecciones autonómicas, en virtud de la D.A. primera, apartado 2 de la propia LOREG, si bien pueden

\footnotetext{
${ }^{12}$ El único supuesto en que la declaración de un estado excepcional puede afectar a dicho derecho es el contemplado en la Ley Orgánica 2/1980, de 18 de enero, sobre regulación de las distintas modalidades de referéndum, que en su artículo 4 dispone que "no podrá celebrarse referéndum en ninguna de sus modalidades durante la vigencia de los estados de excepción y sitio en alguno de los ámbitos territoriales en los que se realiza la consulta o en los noventa días posteriores a su levantamiento". Como puede verse, el estado de alarma no afectaría a dichos procesos.
} 
resultar de aplicación supletoria en virtud del apartado 3 de dicha disposición ${ }^{13}$. Parece claro que ninguno de estos preceptos puede servir, siquiera remotamente, para suspender un proceso electoral en su conjunto.

Nos encontramos, pues, ante un vacío normativo. Un vacío que podría haber sido colmado por el legislador estatal mediante una reforma de urgencia de la LOREG (Tajadura Tejada, 2020; Presno Linera, 2020a), pero que, ante la inacción de éste, fue sencillamente obviado por los Presidentes de ambas comunidades autónomas, los cuales, simple y llanamente, se arrogaron la competencia para desconvocar lo que habían previamente convocado. Una solución, desde luego, jurídicamente discutible (Castellá Andreu, 2020: 2) y que algunos autores no dudaron en calificar de "chapucera" (Presno Linera, 2020a).

Según informaciones periodísticas (Casqueiro et al., 2020), los Gobiernos vasco y gallego plantearon, ya antes de la declaración del estado de alarma, la posibilidad de suspensión de los procesos electorales y manifestaron públicamente que tal decisión debía corresponder, ante la ausencia de normativa aplicable, a la Junta Electoral Central. De acuerdo con dichas informaciones, la Junta Electoral Central abordó el asunto informalmente en una de sus reuniones y llegó a la conclusión de que, en el caso de que la situación lo exigiese, la competencia para decidir sobre la suspensión de los procesos electorales debía recaer en el órgano convocante, sugiriendo asimismo que se contase con la anuencia de las Juntas Electorales autonómicas.

Esa fue, precisamente, la solución que se adoptó por los Presidentes de las comunidades autónomas afectadas. No eluden el problema de la falta de previsión por la legislación electoral vigente del supuesto de suspensión de las elecciones, pero, ante el vacío normativo, se arrogan una supuesta facultad de disposición sobre el proceso electoral, dando por sentado que de la competencia para convocar se deriva la competencia para dejar sin efecto lo convocado, una asunción que contradice la más elemental intuición democrática.

${ }^{13}$ Este sería el caso de Galicia, ya que la Ley 8/1985, de 13 de agosto, de elecciones al Parlamento de Galicia no contempla estos supuestos. En cambio, la Ley 5/1990, de 15 de junio, de Elecciones al Parlamento Vasco sí que contempla en su artículo 102.1 la suspensión de la votación por causa de fuerza mayor y en su artículo 117.2 la suspensión del escrutinio debido a alteraciones del orden. 
Así, en la exposición de motivos del Decreto 7/2020, de 17 de marzo, del Lehendakari, por el que deja sin efecto la celebración de las elecciones al Parlamento Vasco del 5 de abril de 2020, se dice expresamente que "el artículo 46 de la Ley 5/1990, de elecciones al Parlamento Vasco y el artículo 51 de la Ley 7/1981, sobre ley de Gobierno, confieren al Lehendakari la capacidad para realizar la convocatoria de elecciones al Parlamento Vasco fijando la fecha de votación (...)", "[f]acultades que también se mantienen tras la publicación de dicho Decreto [el de convocatoria] y hasta la celebración de las elecciones".

Por su parte, el Decreto 45/2020, de 18 de marzo, por el que se deja sin efecto la celebración de las elecciones al Parlamento de Galicia de 5 de abril de 2020, señala también en su exposición de motivos que el mismo se dicta "en ejercicio de las atribuciones conferidas por la Ley 1/1983, de 22 de febrero, de normas reguladoras de la Xunta y de su Presidencia, y por la Ley 8/1985, de 13 de agosto, de elecciones al Parlamento de Galicia”.

Dicho esto, a los redactores de las exposiciones de motivos de ambos decretos debió de parecerles bastante endeble la apoyatura formal y, por ello, se preocuparon de dejar bastante clara la auténtica fundamentación de la decisión, que no es otra que la necesidad. Así lo viene a reconocer el Decreto del Lehendakari cuando dice que "el silencio de la ley no excluye la necesidad de una regla de conducta para casos no previstos en ella, atendiendo a los principios generales contenidos en la propia legislación electoral" y, en la misma línea apunta el Decreto del Presidente de la Xunta cuando señala que "ante el silencio legal" resulta obligado "buscar una solución integradora y conforme al bloque de constitucionalidad". El problema es que esa "legislación electoral" y ese "bloque de constitucionalidad" al que los decretos dicen acudir para colmar el vacío legal no ofrecen prácticamente nada a lo que agarrarse para fundamentar que sean precisamente los Presidentes de las comunidades autónomas los encargados de paralizar los procesos electorales.

Ciertamente, tanto en el caso del País Vasco, como en el de Galicia, los Presidentes adoptan la decisión tras consultar con las respectivas Juntas Electorales, que consideran ajustada a Derecho la solución adoptada ${ }^{14}$, y tras

\footnotetext{
${ }^{14}$ La Junta Electoral del País Vasco no adoptó un acuerdo, sino que emitió una posición sobre la comunicación recibida desde el Gobierno Vasco. Véase el Acta de la reunión de la Junta
} 
lograr el consenso con las fuerzas políticas representadas en los respectivos parlamentos. Ambos pasos, no exigidos por el procedimiento -porque no hay procedimiento- responden a la voluntad, sin duda loable, de revestir de legitimidad material a decisiones que carecen de ella desde un punto de vista formal.

La solución adoptada ha recibido numerosas críticas. Probablemente, una de las más severas ha sido la de Fernández-Fontecha, para quien "las medidas de aplazamiento electoral son inconstitucionales, de raíz" y suponen entrar en "un mundo desconocido, el de la ilegalidad", una ilegalidad que no se ve mitigada, a juicio de este autor, por la intervención de las juntas electorales, ya que estos órganos carecen de competencias para el aplazamiento o la suspensión de las elecciones (Fernández-Fontecha, 2020: 1).

En mi opinión, si admitimos que nos encontramos ante una situación en la que, para preservar determinados bienes y derechos -de los que hablaremos después-, existe una necesidad imperiosa de adoptar una decisión para la que no existe una cobertura legal, entonces, lo adecuado es tratar de adoptar dicha decisión con las máximas garantías posibles. Pienso que los decretos de los Presidentes autonómicos pretendieron precisamente eso: dotar a la decisión de las máximas garantías, entre las que se encontraba el propio control judicial de los mismos, llegado el caso.

Una solución distinta, y quizás más escrupulosa, habría sido que las propias Juntas Electorales autonómicas, o la Junta Electoral Central, hubiesen adoptado directamente la decisión, ya que se trata de órganos garantes de la equidad de la competición electoral y están sometidos a un mandato de estricta neutralidad. Esta solución fue inicialmente defendida, entre otros, por Tajadura Tejada (Casqueiro et al., 2020). Sin embargo, ante la inhibición de la Junta Electoral Central, alegando su falta de competencias, los Presidentes

Electoral de la Comunidad Autónoma del País Vasco celebrada el 17 de marzo de 2020, pp. 78 (http://www.legebiltzarra.eus/portal/documents/16182/1328761/20200317_akta_ec.pdf). En cuanto a la Junta Electoral de Galicia, véase Acuerdo de 18 de marzo de 2020 sobre la suspensión de las elecciones al Parlamento (http://www.poderjudicial.es/cgpj/es/PoderJudicial/Tribunales-Superiores-de-Justicia/TSJ-Galicia/Sala-de-prensa/Notas-deprensa/Acuerdo-de-la-Junta-Electoral-de-Galicia-sobre-la-suspension-de-las-elecciones-alParlamento-). 
autonómicos se encontraron ante la imperiosa necesidad de actuar y salieron del paso, a mi juicio, de la mejor manera posible, dadas las circunstancias.

Ahora bien, que la solución adoptada en este caso pueda ser válida, dada la situación concreta y contando con el máximo consenso político, no puede llevarnos en absoluto a admitir pro futuro la competencia de los órganos convocantes para desconvocar o aplazar los procesos electorales ante situaciones de fuerza mayor que impidan su desarrollo. ¿Qué podría pasar si nos encontrásemos ante situaciones más dudosas en las que no exista un amplio consenso político? Creo que es evidente que dejar en manos del ejecutivo la paralización de una convocatoria electoral supone un peligro de deslegitimación del proceso inasumible en democracia, incluso aunque dicha decisión esté sometida a control judicial.

Es necesaria, pues, una regulación legal más precisa, tanto de las circunstancias que pueden suponer un aplazamiento electoral -que deben ser previstas de manera extremadamente restrictiva y quizás vinculadas a la declaración de estados excepcionales (en este sentido, Tajadura Tejada, 2020)-, como del procedimiento para adoptarlo, con el fin de garantizar, como ha señalado un autor, "que la decisión no se toma unilateralmente" (Vidal Prado, 2020: 219, 220). En mi opinión, debería otorgarse dicha competencia a las Juntas Electorales o, al menos, exigir su autorización previa. Coincido con Castellà Andreu en que el papel secundario jugado por las Juntas en esta ocasión no parece el más adecuado, pues, como señala este autor, "deberían haber sido las autoridades electorales las que asumieran el protagonismo en la decisión, dada su posición supra partes y garantista de la integridad del proceso electoral" (Castellà Andreu, 2020: 2). Asimismo, creo que es necesaria también, en el marco de la imprescindible e inaplazable revisión de la regulación de los estados excepcionales, abordar la cuestión, no resuelta aún de forma satisfactoria, de cómo afectan estos estados a los procesos electorales en curso. 


\section{La razonabilidad y la proporcionalidad de las medidas de suspensión de los procesos electorales}

En el apartado anterior he afirmado que la solución adoptada puede ser válida, si admitimos que nos encontrábamos ante una situación de imperiosa necesidad. Pero, ¿es esto realmente así? ¿Estaba realmente justificado el aplazamiento?

Las restricciones de derechos fundamentales deben tener una justificación objetiva y razonable. Básicamente, se trata de limitar ciertos derechos para preservar otros bienes o derechos que, bajo determinadas condiciones, se considera que deben prevalecer.

Las justificaciones aducidas en las exposiciones de motivos de ambos decretos son muy similares y se refieren fundamentalmente a la incidencia que las medidas de restricción de la movilidad, de suspensión de actividades, de cierre de establecimientos y locales y de aislamiento social, pueden tener para la campaña electoral y para la jornada de la votación. En ambos casos, con similares razonamientos, se concluye que no es posible garantizar el normal desarrollo de los procesos electorales sin que se afecte al derecho de participación de la ciudadanía y al libre ejercicio del derecho de sufragio ${ }^{15}$.

\footnotetext{
${ }^{15}$ De acuerdo con la exposición de motivos del Decreto 45/2020, de 18 de marzo, por el que se deja sin efecto la celebración de las elecciones al Parlamento de Galicia de 5 de abril de 2020 como consecuencia de la crisis sanitaria derivada del COVID-19, "[l]as medidas adoptadas (...) resultan, con todo, incompatibles con el normal desarrollo de un proceso electoral y, por tanto, del libre y normal ejercicio del derecho de sufragio". "Además, [prosigue] de prorrogarse la vigencia del estado de alarma y abarcar el propio día de la votación, el cierre comprendería lugares previstos como locales electorales, además de que las medidas relativas a la limitación de la libertad de circulación de personas impedirían, asimismo, el desarrollo de la jornada electoral con las garantías que el derecho fundamental de sufragio impone". En términos muy similares, la exposición de motivos del Decreto 7/2020, de 17 de marzo, del Lehendakari, por el que deja sin efecto la celebración de las elecciones al Parlamento Vasco del 5 de abril de 2020, debido a la crisis sanitaria derivada del Covid-19, y se determina la expedición de la nueva convocatoria, viene a señalar que "[l]as medidas de suspensión de actividades públicas y de aislamiento social para contener la propagación del virus suponen un impedimento a la realización de las normales actividades de propaganda y captación de sufragios propia de la campaña electoral". Por otra parte, reconoce que las medidas preventivas que se habían previsto para la jornada de la votación resultan "insuficientes (...) para garantizar la protección de la salud pública y el normal desenvolvimiento de las elecciones sin que se afecte al derecho de participación de la ciudadanía y al libre ejercicio del derecho de sufragio".
} 
El razonamiento que subyace a ambos decretos es el mismo y se puede resumir de la siguiente forma: como las medidas que se han adoptado para contener la transmisión del virus impiden la normal celebración de las elecciones, entonces éstas no pueden celebrarse. A mi modo de ver, existía otro posible razonamiento, más respetuoso con el ejercicio del derecho de participación: ¿Cabe una modulación de las medidas de contención de la pandemia que posibilite la celebración del proceso electoral? Es decir, aplicando el juicio de necesidad propio de cualquier medida limitativa de los derechos fundamentales, podríamos habernos preguntado si existían otras medidas posibles para preservar la vida y la salud de las personas frente al riesgo de la pandemia que no impidiesen el ejercicio del derecho de participación política de los ciudadanos.

Personalmente, no me atrevo a dar una respuesta categórica a dicha pregunta. Pero lo que sí que puedo decir es que entre marzo y mayo -periodo que coincide con la máxima expansión de la primera oleada de la pandemia- se llevaron a cabo procesos electorales en diversos países ${ }^{16}$, quedando, a mi juicio, suficientemente demostrado que, con ciertas condiciones, las elecciones se pueden celebrar con garantías de seguridad. Como señala De Guttry (2020: VI), la experiencia de estos países nos muestra que se puede minimizar el riesgo de difusión de la pandemia, protegiendo la salud de los electores y del personal interviniente en el proceso y garantizar, al mismo tiempo, el libre desarrollo del proceso electoral.

Sin duda, Corea del Sur constituye el mejor ejemplo de buena gestión de las elecciones en una situación de pandemia, logrando incluso batir records de participación electoral (International IDEA, 2020: 5). Este país celebró sus elecciones parlamentarias nacionales el 15 de abril, en plena primera ola de la

${ }^{16}$ Como ya hemos indicado al comienzo de este trabajo, en Europa se pueden citar, entre otros, los casos de Francia (primera vuelta de las elecciones locales, 15 de marzo), Alemania (Land de Baviera, 15 y 29 de marzo) y Suiza (elecciones cantonales de Turgovia, 15 de marzo, y Schwytz, 22 de marzo). Fuera de Europa se pueden citar, entre otros, los casos de República Dominicana (15 de marzo), Bangladesh (elecciones parlamentarias parciales y gubernamentales locales, 21 de marzo), Australia (elecciones locales en Queensland, 29 de marzo), Camerún (elecciones parlamentarias parciales, 22 de marzo), así como numerosas elecciones primarias en diversos estados de los EEUU. Destaca sobre todo el caso de Corea de Sur, que mantuvo sus elecciones parlamentarias del 15 de abril. Una información más detallada sobre los procesos electorales mantenidos y suspendidos se puede encontrar en International IDEA, Global overview of COVID-19: Impact on elections: https://www.idea.int/news-media/multimedia-reports/global-overview-covid-19-impact-elections 
expansión del virus, y ha sido ampliamente elogiado por garantizar eficazmente la salud pública, permitiendo la plena participación de todos los ciudadanos, incluidos los que estaban infectados con el virus. Las autoridades electorales llevaron a cabo una adaptación de los procedimientos, destacando el uso masivo de tests de detección de la infección junto con las medidas de distanciamiento social y el acondicionamiento de los espacios físicos. Pero, quizás, lo que más contribuyó a las altas tasas de participación fue la confianza de los ciudadanos en la respuesta general de su Gobierno frente a la pandemia $^{17}$.

Desde el punto de vista de la proporcionalidad, la adopción de una medida de suspensión o aplazamiento de un proceso electoral debe basarse en un delicado equilibrio entre todos los derechos o intereses en juego. De una parte, obviamente, los derechos a la vida y a la salud de la población que pueden ponerse en riesgo tanto durante la campaña, como durante la propia jornada de la votación. De otra parte, el derecho de los ciudadanos a participar en los asuntos públicos a través de elecciones libres celebradas a intervalos regulares.

Tanto la celebración como la no celebración de los comicios pueden tener consecuencias muy graves en todos estos derechos. De una parte, la celebración de las elecciones sin unas medidas de seguridad garantizadas puede tener efectos disuasivos sobre la participación y, por ende, afectar a la universalidad del sufragio, lo que puede conducir a poner en cuestión la propia legitimidad del proceso electoral en su conjunto. No puede desdeñarse el riesgo de que algunos gobernantes, ante la probabilidad de que el miedo a la pandemia reduzca significativamente la afluencia a las urnas, decidan intencionadamente seguir adelante con el proceso electoral pensando que la baja participación favorecerá sus posibilidades para permanecer en el poder. Asimismo, las restricciones a otros derechos, como las libertades de reunión y manifestación, que implican dificultades para celebrar actos públicos de campaña, pueden tener también efectos muy serios sobre la libertad de la elección. De otra parte, la decisión de suspender o posponer las elecciones, aunque sea por un tiempo limitado, también puede suponer un riesgo de

\footnotetext{
17 Sobre la respuesta general dada a la pandemia en este país puede consultarse el documento publicado por el propio gobierno (Government of the Republic of Korea, 2020).
} 
debilitamiento del control democrático de los gobernantes, especialmente en países en proceso de consolidación democrática.

La Comisión de Venecia (2020: 28) lo ha expresado en términos muy similares, señalando que "el principio de proporcionalidad es la clave", a lo que añade, como ya hemos indicado al comienzo de este trabajo, que "[e]n particular, toda restricción destinada a garantizar la celebración puntual de elecciones debe ponderarse con la limitación del derecho a elecciones libres debido a la situación de emergencia y, a la inversa, el aplazamiento de las elecciones debe ponderarse con el riesgo de celebrarlas durante la situación de emergencia”.

\section{DESARROLLO DEL PROCESO ELECTORAL Y MEDIDAS PROTECTORAS}

Las decenas de procesos electorales que se han llevado a cabo durante 2020 han producido un laboratorio vivo de buenas prácticas. Muchos países se han visto obligados a introducir modificaciones legislativas y adaptaciones administrativas para garantizar la seguridad de las operaciones electorales sin por ello disminuir sus garantías. Asimismo, las autoridades electorales se han reunido en distintos foros internacionales con el fin de poner en común sus experiencias y desde diversas instancias se han emitido recomendaciones destinadas a garantizar la compatibilidad entre los derechos a la vida y a la salud y el pleno ejercicio de los derechos democráticos de la ciudadanía (Buril et al., 2020; British Academy, 2020).

Así pues, a estas alturas disponemos ya de un amplio catálogo de medidas que han sido ya puestas en práctica en diferentes países del mundo. En un trabajo de alcance limitado como el presente no tiene ningún sentido extenderse en una exposición detallada de todas ellas. Baste con distinguir dos grandes bloques: (a) medidas para favorecer el voto no presencial por diversos métodos, en particular mediante el voto telemático, el voto anticipado o el voto por correspondencia; y (b) medidas para asegurar las mejores condiciones sanitarias para el voto presencial: acondicionamiento de locales, protección del personal implicado, adaptación de los horarios de votación, así como medidas especiales para determinadas categorías de personas, como las internadas en 
residencias de mayores, las hospitalizadas o las contagiadas con el virus en situación de confinamiento.

En España, cuando finalmente, una vez superada la primera oleada de la pandemia, se decidió la celebración de las elecciones autonómicas en el País Vasco y Galicia el día 12 de julio ${ }^{18}$, se optó por iniciar de nuevo los procesos electorales desde el principio -solución más correcta y garantista, como han señalado, entre otros Arnaldo Alcubilla (2020)-. Previamente, el Gobierno de la Nación había aprobado el Real Decreto 514/2020, de 8 de mayo, por el que se prorrogaba el estado de alarma por cuarta vez, y en que se incluyó una Disposición final primera, que modificaba el Real Decreto 463/2020 añadiendo un nuevo apartado 1 bis al artículo 7, indicando que "la vigencia del estado de alarma no supondrá obstáculo alguno al desenvolvimiento y realización de las actuaciones electorales precisas para el desarrollo de elecciones convocadas a Parlamentos de comunidades autónomas". Esta disposición, como señala Cebrián Zazurca (2020: 27), no puede ser entendida en ningún caso como una autorización para convocar elecciones, sino más bien como una simple aclaración por la que se confirma que el estado de alarma en sí no constituye ningún impedimento para el desarrollo de procesos electorales.

En estos nuevos procesos electorales se adoptaron una serie de medidas especiales para favorecer el ejercicio del derecho de sufragio en condiciones de seguridad. Entre ellas, destaca la flexibilización del procedimiento de voto por correspondencia para favorecer su utilización. Asimismo, dedicaremos algunos comentarios a las decisiones de las administraciones del País Vasco y de Galicia, avaladas por las Juntas Electorales autonómicas, por la Junta Electoral Central e incluso, provisionalmente, por el Tribunal Supremo, mediante las cuales se privaba del derecho de sufragio a personas infectadas con el SARS-Cov-2.

\footnotetext{
${ }^{18}$ Decreto 11/2020, del Lehendakari, por el que se convocan elecciones al Parlamento Vasco; Decreto del Presidente de la Xunta, el 72/2020, de convocatoria de elecciones al Parlamento de Galicia.
} 


\section{La flexibilización del voto por correspondencia: un cuestionable recorte de garantías}

Respondiendo a una consulta planteada por el Presidente del Grupo Correos, la Junta Electoral Central (JEC) aprobó el Acuerdo 56/2020, de 28/05/2020, por el cual se adoptan una serie de medidas relativas a la tramitación del voto por correo "para la protección de la salud pública y de los trabajadores de Correos". Sin duda, tanto la consulta, como la respuesta del organismo de control electoral están directamente relacionadas con la nueva disposición adicional séptima incorporada por el Real Decreto 514/2020, antes citado, al Real Decreto 463/2020, en la que el Gobierno se autoimpone la obligación de disponer lo que considere "oportuno para que el servicio público de correos, los fedatarios públicos y demás servicios de su responsabilidad coadyuven al mejor desenvolvimiento y realización de elecciones convocadas a Parlamentos de Comunidades Autónomas".

El Acuerdo de la JEC 56/2020 supone una significativa flexibilización de los trámites del voto por correo, al permitir (1) que el elector lo solicite de forma telemática, mediante firma electrónica, sin necesidad de desplazarse a una oficina de Correos $^{19}$, (2) que en el momento de la entrega de la documentación al elector en su domicilio, este no esté obligado a firmar, sino que baste con que el empleado de Correos compruebe su identidad mediante la exhibición del DNI o de cualquier otro documento oficial, y (3) que, en el mismo momento de la entrega de la documentación, el elector tenga la posibilidad de entregar su voto al empleado de Correos, evitándole el tener que acudir posteriormente a una oficina de Correos.

Estamos ante unas disposiciones que, cuando menos, en palabras de uno de los miembros de la JEC, "se sitúan al límite de lo dispuesto en la legislación, si no lo desbordan" (Vidal Prado, 2020: 222). Una vez más, ante la ausencia de previsión legislativa y ante la inacción del legislador, que ha dispuesto de tiempo más que suficiente para haber llevado a cabo una reforma exprés de la normativa aplicable, ha sido preciso dar respuesta a una situación de necesidad acudiendo a una vía más que dudosa. Coincido con Cebrian

\footnotetext{
${ }^{19}$ Cabe señalar que esta adaptación se va a mantener de manera general, sin necesidad de encontrarse en situaciones de emergencia sanitaria o de otro tipo, por decisión de la JEC en respuesta a una consulta del Presidente de Correos (AJEC 162/2020, de 22 de octubre).
} 
Zazurca (2020: 32) cuando señala que "lo correcto habría sido proceder, en su caso, a una reforma de la LOREG que contemplase estos cambios, habilitándolos al menos para cuando se diesen determinadas circunstancias".

Por otro lado, el propio contenido de las flexibilizaciones operadas por la JEC resulta enormemente problemático por la merma de garantías que provoca en relación con la personalidad, libertad y secreto del voto (en el mismo sentido, Cebrián Zazurca, 2020: 33). Recordemos a este respecto que los requisitos que ahora se han eliminado fueron introducidos mediante la Ley Orgánica 6/1992, de 2 de noviembre, precisamente con el fin de poner coto a situaciones reales de fraude que se habían detectado en la práctica electoral. Esta misma preocupación es la que ha motivado que el Defensor del Pueblo solicitase a la JEC la modificación del Acuerdo 56/2020, en el sentido de exigir la firma del elector al recibir la documentación electoral, solicitud que fue respondida negativamente mediante el Acuerdo de la JEC 91/2020, de 25 de junio. Hay que señalar, igualmente, que la JEC ha decidido, mediante el Acuerdo 192/2020, de 19 de noviembre, extender las medidas de flexibilización del voto por correo en el caso de unas posibles elecciones al Parlamento de Cataluña a celebrar el 14 de febrero de 2021.

\section{La privación del derecho de sufragio de personas infectadas o sospechosas de estarlo}

Debemos detenernos ahora en un episodio bochornoso que concluyó con la privación, en la práctica, del derecho de sufragio de centenares de personas, sin la más mínima base legal que avalase tamaño despropósito. Un episodio donde la incomprensible improvisación de las autoridades autonómicas fue de la mano con la no menos incomprensible pasividad de los órganos de control electoral. Nos detendremos en este episodio muy brevemente, pues ya la doctrina se ha pronunciado con suficiente contundencia (Presno Linera, 2020b; Cebrián Zazurca, 2020; Pérez Royo, 2020, entre otros).

Una vez convocadas por segunda vez las elecciones autonómicas gallegas y vascas, los rebrotes de Covid-19 en determinadas zonas (el municipio de Ordizia en Gipuzkoa y la comarca de A Mariña en Lugo) motivaron que las autoridades autonómicas adoptaran ciertas decisiones administrativas que, en 
la práctica, supusieron la privación del derecho de sufragio para cientos de personas.

Lo primero que hay que aclarar es que en ninguna de las dos Comunidades se adoptó ninguna disposición general o resolución individual que prohibiese expresamente el derecho de voto de las personas infectadas o sospechosas de estarlo. En el caso de las personas infectadas, su imposibilidad fáctica para votar derivaba de su sometimiento a medidas individuales de confinamiento domiciliario. En el caso de las personas con síntomas compatibles con la infección, su imposibilidad fáctica para votar derivaba de las medidas especiales acordadas por las autoridades sanitarias autonómicas en relación con los municipios anteriormente citados en los que se habían producido rebrotes de cierta gravedad, en las cuales se decretaba su confinamiento domiciliario obligatorio ${ }^{20}$.

La imposibilidad para ejercer el derecho de voto derivó, pues, en primer término, de la interpretación que hicieron las autoridades autonómicas -mediante declaraciones públicas, no mediante normas o actos administrativos-, señalando que las situaciones de confinamiento domiciliario obligatorio tenían como consecuencia inevitable la privación del derecho de sufragio de las personas contagiadas o sospechosas de estarlo -salvo que hubieran solicitado el voto por correo antes del 2 de julio- $y$, en segundo término, de la inacción de esas mismas autoridades, y de las propias juntas electorales competentes, a la hora de buscar alternativas que hicieran posible el ejercicio del derecho.

¿Una medida de confinamiento domiciliario obligatorio conlleva necesariamente la imposibilidad de votar presencialmente? En mi opinión no tiene por qué ser así. No es el ejercicio del derecho de sufragio el que debe interpretarse $-\mathrm{y}$, en su caso, suspenderse - a la luz de las medidas restrictivas de la libertad de circulación, sino al revés, son las medidas restrictivas de la libertad de

\footnotetext{
${ }^{20}$ Orden de 5 de julio de 2020 por la que se establecen determinadas medidas de prevención en los ayuntamientos de Alfoz, Barreiros, Burela, Cervo, Foz, Lourenzá, Mondoñedo, Ourol, Ribadeo, Trabada, O Valadouro, O Vicedo, Viveiro e Xove, como consecuencia de la evolución de la situación epidemiológica derivada del COVID-19 (Diario Oficial de Galicia de 5 de julio de 2020); Orden de 8 de julio de 2020, de la Consejera de Salud, por la que se adoptan medidas especiales en materia de salud pública para la contención del brote epidémico de la pandemia COVID-19, en el municipio de Ordizia (Boletín Oficial del País Vasco de 9 de julio de 2020).
} 
circulación las que deben interpretarse para hacer posible el ejercicio del derecho de sufragio.

¿Había alternativas? A mi juicio, sí y sin necesidad de forzar la interpretación de las normas o, en todo caso, sin necesidad de forzarla mucho más de lo que se había hecho en otras ocasiones, sin ir más lejos, por ejemplo, a la hora de aplazar los propios procesos electorales.

Creo que habría sido posible haber previsto franjas temporales específicas de votación para las personas infectadas. De hecho, las autoridades del País Vasco recomendaron a los contactos estrechos, que sí podían votar, que lo hicieran entre las 14 y las 15 horas, por ser esta franja la de menor afluencia. ¿Qué problema habría supuesto aplicar esta misma medida a los infectados? Estaríamos entonces ante una limitación razonable de su derecho de sufragio, no ante una suspensión del mismo.

Ciertamente seguía existiendo el problema del riesgo de contagio por la manipulación del sobre y las papeletas. Por ello, creo que habría sido posible aplicar de forma analógica el supuesto del voto asistido, previsto en el artículo 87.1 LOREG, el cual dispone que "los electores que no sepan leer o que, por discapacidad, estén impedidos para elegir la papeleta o colocarla dentro del sobre y para entregarla al Presidente de la Mesa, pueden servirse para estas operaciones de una persona de su confianza". Aunque no se trata de una situación de incapacidad, las personas infectadas se ven impedidos para elegir la papeleta, colocarla dentro del sobre y entregarla al Presidente de la Mesa. ¿No habría sido una solución admisible permitir que se sirvieran de la asistencia de una persona de su confianza?

Incluso, si se hubiera querido evitar a toda costa la entrada de estas personas en el colegio electoral, habría sido posible prever que el Presidente de la Mesa saliese a recoger el voto a la puerta del local, como se hace en ocasiones especiales en las que los electores tienen una discapacidad motora y el local no está adaptado.

Lo que sucedió, simplemente, es que las autoridades autonómicas de Galicia y del País Vasco no previeron métodos alternativos para que los afectados por covid-19 pudieran votar presencialmente, de manera que todas aquellas 
personas infectadas que no hubieran solicitado el voto por correo antes de la finalización del plazo para hacerlo, se quedaron sin poder ejercer el derecho al voto. Esta falta de previsión ha sido, incluso, puesta de manifiesto por la propia JEC que, en relación con la cuestión de las dificultades planteadas para la solicitud del voto por correo mediante representante, había ya manifestado ${ }^{21}$ que:

“(...) desde el momento en que fue autorizada la convocatoria de las presentes elecciones en el marco de una situación de pandemia que iba a afectar durante meses cuando menos, a la mayoría de los países del mundo, debió preverse la ineludible aparición de riesgos y obstáculos que dificultarían e, incluso, podrían llegar a impedir ocasionalmente el normal ejercicio del derecho de sufragio por los electores (...)".

En relación con la posible ampliación del plazo de voto por correo para estas personas, las coaliciones En Marea-Compromiso por Galicia-Partido Galeguista-Marea Galeguista y Galicia en Común-Anova Mareas solicitaron que se permitiese aplicar las que fueron arbitradas por la JEC para facilitar el voto por correo de los miembros de las fuerzas y cuerpos de seguridad del Estado desplazados en Cataluña en las elecciones generales del 10 de noviembre de 2019, método que fue avalado por el Tribunal Supremo (Sala Tercera) en su Auto de 8 de noviembre de 2019. La Junta electoral de Galicia rechazo dichas solicitudes ${ }^{22}$ y la JEC, a su vez, rechazó también los recursos de alzada presentados por las coaliciones recurrentes ${ }^{23}$.

La JEC se pronunció con carácter general sobre las medidas adoptadas por las administraciones en los Acuerdos 126/2020, 127/2020, 128/2020 y 129/2020 en los siguientes términos:

"En estos precisos momentos debe entenderse que las medidas adoptadas por la Administración garantizan unas condiciones adecuadas

\footnotetext{
${ }^{21}$ Acuerdo de la JEC 93/2020, de 25 de junio.

${ }^{22}$ Acuerdos de 7 de julio de 2020.

${ }^{23}$ Acuerdos de la JEC 126/2020 y 127/2020, de 9 de julio. En el mismo sentido se pronunció el Acuerdo de la JEC 128/2020, de 17 de julio, pero esta vez en relación con un recurso presentado por la coalición Elkarrekin Podemos-IU contra los acuerdos2020/357, de 9 de julio, y 2020/360, de 10 de julio, adoptados por la Junta Electoral de la Comunidad Autónoma del País Vasco.
} 
de circulación para poder acudir a votar, con la salvedad de segmentos reducidos de población, por motivos sanitarios suficientemente justificados en el marco de la situación de pandemia en la que se están desarrollando las elecciones".

En la resolución de la Presidencia de la JEC de 11 de julio de 2020, cuyo contenido fue posteriormente reiterado por los Acuerdos 128/2020 y 129/2020, de 17 de julio, se decía también que las medidas adoptadas por la Administración de la Comunidad Autónoma del País Vasco:

“(...) de manera motivada, proporcionada y adecuada, responden a la finalidad de salvaguardar otro derecho fundamental esencial, el derecho inviolable a la vida e integridad física de las personas, consagrado en el artículo 15 de la Constitución Española (...) y también, el derecho a la protección de la salud reconocido en el artículo 43 de la Constitución (...)".

Cabe señalar también que la solicitud de medidas cautelarísimas por parte de Galicia en Común-Anova-Mareas a la Sala Tercera del Tribunal Supremo, en el marco del recurso contencioso-administrativo interpuesto contra el Acuerdo de la JEC 127/2020, antes citado, con el fin de "(...) garantizar que todas las vecinas y vecinos de la comarca de A Mariña actualmente confinados puedan ejercer, democráticamente y con todas las garantías sanitarias, su derecho fundamental al voto en las elecciones al Parlamento de Galicia del próximo 12 de julio (...)" fue rechazada por la Sección 4ํㅡㄹ de dicha Sala el 11 de julio de 2020 por entender que se trataba de una pretensión absolutamente genérica e indeterminada.

Coincido con Cebrián Zazurca (2020: 35) en que se produjo "una evidente conculcación del derecho fundamental de sufragio de todas aquellas personas enfermas que no pudieron ejercerlo". Una conculcación que habría podido evitarse de haber existido una voluntad clara y una actitud más proactiva por parte de las Administraciones implicadas y de los órganos de control electoral.

De cara al futuro, entiendo, con Vidal Prado (2020: 223) que es necesario que la LOREG y las legislaciones autonómicas se adapten y prevean este tipo de situaciones con el fin de garantizar el pleno ejercicio del derecho de sufragio de 
aquellas personas que se encuentren en situaciones de movilidad restringida como consecuencia de medidas de confinamiento ligadas a crisis sanitarias 0 de otro tipo.

A mi juicio, las carencias que se han puesto en evidencia en esta situación nos muestran que cada vez es más necesario abordar una profunda transformación de la Administración electoral en España para alumbrar una potente Autoridad Electoral independiente, dotada de nuevas competencias y de medios suficientes para su cumplimiento. Una primera exigencia de este proceso de institucionalización es la creación de una estructura administrativa permanente y dotada de medios materiales y personales propios, sobre todo con personal técnico especializado, con capacidad de análisis y de investigación que le permita anticiparse a cualquier fenómeno que pueda distorsionar los procesos electorales $^{24}$.

\section{BIBLIOGRAFÍA}

- ARNALDO ALCUBillA, E., "La suspensión de la celebración de las elecciones comporta una convocatoria íntegra", Diario La Ley, núm. 9608, 2020.

- British Academy, How to hold elections safely and democratically during the COVID-19 pandemic, 2020.

- BRUIL, F., DARNOLF, S., ASERESA, M., Cuidando la salud y las elecciones, IFES, mayo de 2020.

- CASTELLÀ ANDREU, J. M., "Incidencia de la Covid-19 sobre la democracia constitucional: reflexiones desde España", Letras libres, 15/04/2020.

- CASqueIRO, J. ORMAZÁBAL, M. y VIZOSO, S., "Las elecciones autonómicas se tambalean", EI País, 12/03/2020.

\footnotetext{
${ }^{24}$ Un ejemplo interesante en este sentido puede ser el de Canada, donde la autoridad electoral está desarrollando un plan operativo para hacer que el voto sea más accesible en situación de pandemia, elevando al Parlamento propuestas de medidas. Las medidas adoptadas por Elections Canada se pueden consultar en su página web: https://www.elections.ca/content.aspx?section=med\&dir=cor\&document=index\&lang=e
} 
- CEBRIÁN ZAZURCA, E., "Covid-19 y anulación de procesos electorales autonómicos en País Vasco y Galicia", Revista General de Derecho Constitucional, núm. 33, 2020.

- Comisión de Venecia, Informe provisional sobre las medidas adoptadas en los Estados miembros de la UE como resultado de la crisis del Covid-19 y su impacto en la democracia, el Estado de derecho y los derechos fundamentales. Aprobado por la Comisión de Venecia en su 124a Sesión Plenaria en línea (8-9 de octubre de 2020).

- DE GUTTRY, A. "Diritto di voto e pandemia: le norme internazionali e gli interventi degli organismi sovranazionali", Federalismi.it, núm 20/2020, págs. IV-XXVII.

- ELLENA, K., Legal Considerations When Delaying or Adapting Elections, IFES, junio de 2020.

- FERNÁNDEZ-FONTECHA, M., declaraciones en “¿Es legal suspender las elecciones autonómicas por el coronavirus?”, EIDerecho.com, 18/03/2020.

- Government of the Republic of Korea, COVID-19, Testing Time for resilience, 2020.

- International IDEA, Administrar elecciones bajo la pandemia COVID-19 La prueba crucial de la República de Corea, Documento técnico 2/2020.

- PÉREZ ROYO, J., "Derecho de sufragio en tiempos de COVID-19", EIDiario.es, 10/07/2020.

- PRESNO LINERA, M. Á., (2020a), "Coranavirus SARS-CoV-2 y derechos fundamentales (5): el derecho de voto (suspensión de elecciones vascas y gallegas)", El derecho y el revés (blog), 03/04/2020.

_ "Prohibido prohibir votar", Agenda Pública-El País, 12/07/2020.

- TAJADURA TEJADA, J., "Estado de alarma y aplazamiento electoral", El Correo, 19/03/2020. 
fundación

Manuel Giménez Abad

deEstudios ParlamentariosydelEstado Autonómico

- United Nations Center for Human Rights, Human Rights and Elections: A Handbook on the Legal, Technical, and Human Rights Aspects of Elections, Geneva, 1994.

- VIDAL PRADO, C., "La celebración de elecciones: una solución controvertida", en Recuerda Girela, Miguel A. (dir.), Antes de la próxima pandemia, Thomson-Reuters Aranzadi, Madrid, 2020, pp. 211-223. 